REVIEW ARTICLE

AFRICAN JOURNAL OF CLINICAL AND EXPERIMENTAL MICROBIOLOGY. JANUARY 2014 ISBN 1595-689X VOL15 No.1

AJCEM/1322

COPYRIGHT 2014 http://dx.doi.org/10.4314/ajcem.v15i1.7

http://www.ajol.info/journals/ajcem

AFR. J. CLN. EXPER. MICROBIOL. 15(1): 40-47

\title{
PAEDIATRIC MALARIA: A TEN-YEAR RETROSPECTIVE STUDY AT THE NATIONAL HOSPITAL, ABUJA, NIGERIA
}

Peletiri, I.C.*; Ajobiewe, J.O.; Ibecheozor, N.K.O.

Medical Microbiology \& Parasitology Laboratories, National Hospital, Abuja, Nigeria

*Correspondence: e-mail: kumochris@hotmail.com Phone no. +2348036426363

\begin{abstract}
A ten year study of malaria amongst paediatric patients was carried out in the Federal Capital Territory, Nigeria, West Africa from 2000 to 2010. Giemsa staining methodology was used. Of the 24289 blood samples analyzed (comprising of 13435 male children and 10854 female children), $8668(35.7 \%)$ were positive for malaria parasites. $267(3.1 \%)$ had parasite density of $>5000$ parasites/ $\mu$ l of blood; $382(4.4 \%)$ had between $500-5000$ parasites/ $\mu$ l of blood; $1262(14.6 \%)$ had between 50 - 500 parasites/ $\mu$ of blood; while $6757(77.9 \%)$ had between 5 - 50 parasites/ $\mu 1$ of blood. The 11-15 years age group had the highest prevalence of 40.6\%, while neonates (<1 - 28 days), 1 month - 5 years, and $6-10$ years age groups recorded 27.2\%, 34.5\% and 36.5\% respectively. Of the 13435 male children, $4845(36.1 \%)$ had positive malaria result as against $35.2 \%(3823)$ of positive cases recorded among the 10854 female children. There is need to enhance parasitological diagnosis by way of providing diagnostic tolls at all levels of health care - primary (rural settings), secondary and tertiary. There are negative implications associated with the continued use of malaria rapid diagnostic tests (M-RDTs) methodologies which includes underdiagnosis, misdiagnosis of malaria and mismanagement of non-malarial fever, which wastes limited resources, erodes confidence in the health care system, and contributes to drug resistance. Finally, appropriate antimalarial drugs for treatment should be given free to all malaria positive children.
\end{abstract}

Keywords: Malaria, paediatric patients, parasite density, prevalence, laboratory diagnosis, treatment.

\section{INTRODUCTION}

The bare facts are that malaria is a public health problem in more than 90 countries inhabited by $40 \%$ of the world's population and that there are $300-500$ million cases annually with a mortality of $1.5-2.7$ million, mainly children in Africa. Malaria infections produce the most severe disease in those with the least immunity. $90 \%$ of the world's malaria is transmitted in the sub-Saharan Africa, and immunity is acquired over time, requiring repeated exposure to the bites of infective Anopheles mosquitos. As a result, young African children are the group at highest risk of developing severe disease. Patwari (1985) (1) reported malaria accounting for between 5 $15 \%$ of deaths of children in endemic areas. However, ten years later, Defo (1995) (2) reported $20-30 \%$ of deaths in childhood being attributed to malaria.

Based on documented cases, the WHO estimates that there were 219 million cases of malaria in 2010 resulting in 660000 deaths (3). This is equivalent to roughly 2000 deaths every day (4). A 2012 study estimated the number of documented and undocumented deaths in 2010 was 1.24 million. The majority of cases $(65 \%)$ occur in children under 15 years old $(5,6)$. Pregnant women are also especially vulnerable: about 125 million pregnant women are at risk of infection each year. In Sub-Saharan Africa, maternal malaria is associated with up to 200000 estimated infant deaths yearly (7).

In Nigeria, the disease is responsible for $60 \%$ of outpatient visits to health facilities, $30 \%$ childhood deaths, $25 \%$ of death in children under one year and $11 \%$ maternal death (8). WHO estimates there were 655000 malaria deaths in 2010, 91\% in the African Region, and $86 \%$ were children under 5 years of age.

More cases of malaria in the neonatal period are being reported which may be due to congenital malaria through transplacental infection, malaria acquired postnatally from mosquito bites or exchange transfusion $(9,10)$.

The problem of malaria had not abated though; Artemisinim-combination therapy (ACT) drugs are in circulation in the drug market aimed at taking care of resistant strains of Plasmodium species. 
The objective of this study therefore is to determine the burden of malaria amongst paediatric patients in the Federal Capital Territory, Nigeria.

\section{METHODS}

\section{Study Area}

The Federal Capital Territory (FCT), Abuja is the study area. Abuja is located between latitude 8.25 and 9.20 north of the Equator and longitude 6.45 and 7.39 east of the Greenwich Meridian. The Federal Capital Territory has a total landmass of about $8000 \mathrm{sq} \mathrm{kms}$; located geographically at the centre of the country. The current population size of the FCT according to the 2006 census figures stands at 1405201 (11).

Two seasons are experienced in FCT. These are the wet (rainy) season and the dry season. The rainy season lasts between April to October (with a mean total rainfall of $62.8-262.7 \mathrm{~mm}$; August being the highest). The dry season is between November and March (with a mean total rainfall of 1.2 to $11.3 \mathrm{~mm}$ ).

Abuja has a daily temperature range between 20.4 $34.7{ }^{\circ} \mathrm{C}$ with an average of $27.2^{\circ} \mathrm{C} / 81^{\circ} \mathrm{of}$ in January; and between $21.9-29.1{ }^{\circ} \mathrm{C}$ with an average of $25.6^{\circ} \mathrm{C} / 78^{\circ} \mathrm{f}$ in July (12).

\section{Study Population}

The population studied consisted of 24289 children (comprising of 13435 males and 10854 females) whose age ranged from day of birth to 15 years whose blood samples were processed at the Parasitology Laboratory of National Hospital, Abuja for malaria parasite diagnosis. This study was carried out from May 2000 to December, 2010.

\section{Parasitological Techniques}

Thick and thin blood films were made on clean grease-free slides and stained appropriately using Giemsa's staining method. The stained films were then examined microscopically using 100x objective to count the parasites.

(3+); $1262(14.6 \%)$ had between $50-500$ parasites $/ \mu 1$ of blood (2+); while 6757 (77.9\%) had between 5-50 parasites $/ \mu$ l of blood $(1+)$ as shown

The 11-15 years age group had the highest prevalence of $40.6 \%$, while neonates ( $<1$ - 28 days), 1 month -5 years, and $6-10$ years recorded $27.2 \%, 34.5 \%$ and
Parasites were counted by estimating the parasite numbers $/ \mu$ l of blood from the thick film. This was carried out by multiplying the average number of parasites per thick film fields (100x objective) by 500 . Between 10 -100 fields (depending on parasiteamia) were examined to determine the average number of trophozoites per thick film fields. Ten fields are sufficient when the parasite density is high.

The factor of 500 was proposed by Greenwood and Armstrong (1991) (13). They calculated that $5-8 \mu \mathrm{l}$ is the volume of blood required to make a satisfactory thick film and that the volume of blood in one thick film fields (100 x objectives) of a well-prepared thick film is about $0.002 \mu \mathrm{l}$. Therefore the number of parasites per thick film field multiplied by 500 gives the estimated number of parasites/ $\mu$ l of blood.

This method, Greenwood and Armstrong (1991) (13) found to be more accurate and quicker than counting the parasites against 100 white blood cells in a thick film using WHO method as used by Molineaux and Gramiccia (1980) (14). In 2002, Ikeh et al, (15) used this technique in their study at Jos.

For designation of the relative parasite count on a thick film, a simple code of from one to four crosses or the plus sign scheme is used to report parasite numbers:

- $+(1+)=1-10$ parasites per 100 thick film fields

- $++(2+) \quad=11-100$ parasites per 100 thick film fields

- $++(3+)=1-10$ parasites per one thick film field

- $++++(4+)=\quad>10 \quad$ parasites per one thick film field

\section{RESULTS}

Of the 24289 samples analyzed, 8668 (35.7\%) were positive for malaria parasites. $267(3.1 \%)$ had parasite density of $>5000$ parasites/ $\mu$ l of blood $(4+) ; 382$ $(4.4 \%)$ had between $500-5000$ parasites $/ \mu 1$ of blood

$36.5 \%$ respectively. The parasite density of each age group is shown in table 1.

Of the 13435 male children, 4845 (36.1\%) had positive malaria result as against $35.2 \%$ (3823) positive cases recorded among the 10854 female children 
TABLE I: PREVALENCE AND PARASITE INTENSITY OF ALL CHILDREN

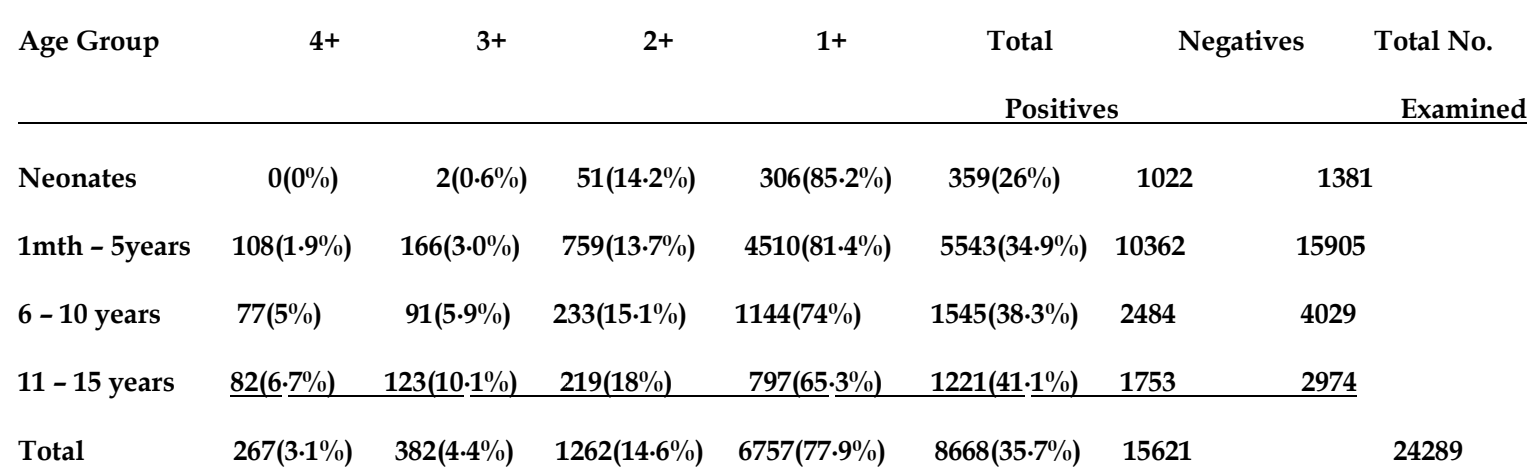

Key: $4+=>5000$ parasites $/ \mu \mathrm{l}$ of blood; $3+=500-5000$ parasites $/ \mu \mathrm{l}$ of blood $; 2+=50-500$ parasites $/ \mu \mathrm{l}$ of blood $1+=5-50$ parasites/ $\mu 1$ of blood

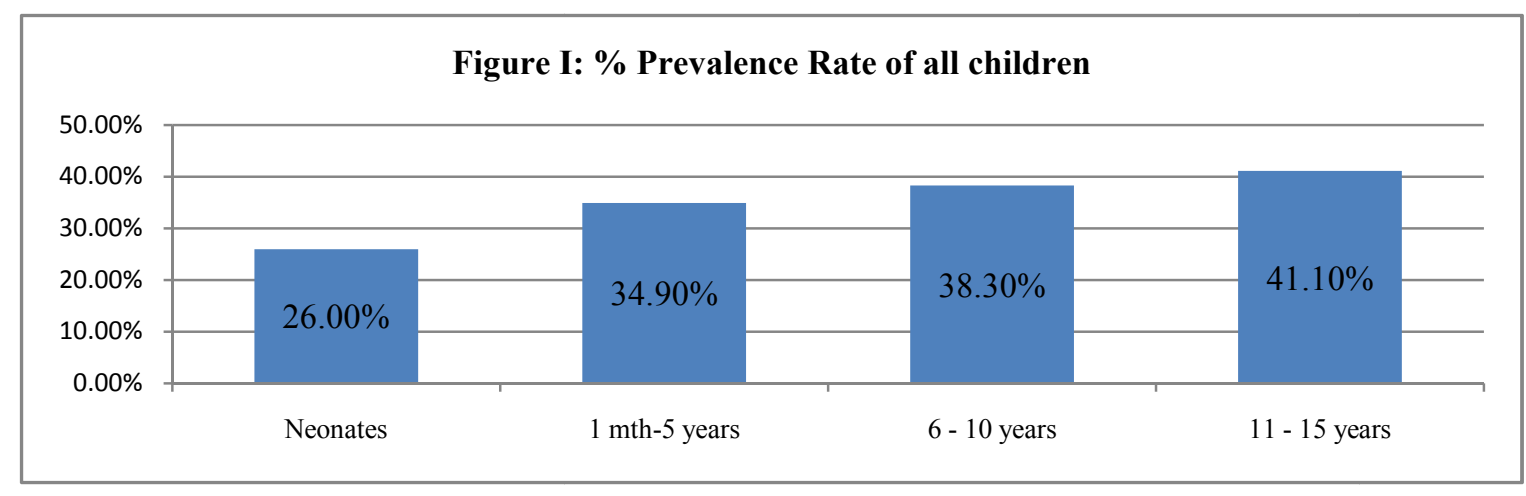

Figure II: \% Positivity of all age groups

11 - 15 years, $14.10 \%$

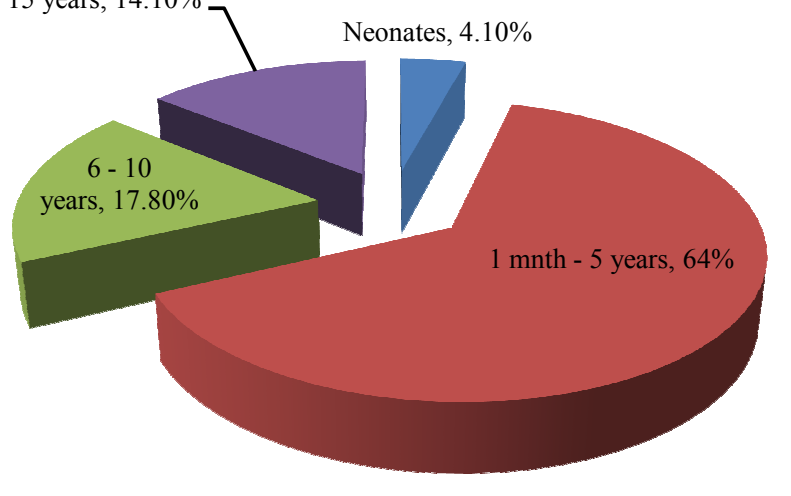

- Neonates

1 mnth - 5 years

6 - 10 years

- 11 - 15 years 
TABLE II: PREVALENCE AND PARASITE INTENSITY OF MALE CHILDREN

\begin{tabular}{|c|c|c|c|c|c|c|c|}
\hline \multirow[t]{2}{*}{ Age Group } & \multirow[t]{2}{*}{$4+$} & \multirow[t]{2}{*}{$3+$} & \multirow[t]{2}{*}{$2+$} & \multirow[t]{2}{*}{$1+$} & Total & \multirow[t]{2}{*}{ Negative } & \multirow{2}{*}{$\begin{array}{l}\text { Total No. } \\
\text { Examined }\end{array}$} \\
\hline & & & & & Positives & & \\
\hline Neonates & $0(0 \%)$ & $1(0.5 \%)$ & $29(15 \cdot 5 \%)$ & $158(84 \%)$ & $188(25 \%)$ & 565 & 753 \\
\hline 1mth - 5years & $65(2 \cdot 1 \%)$ & $91(2 \cdot 9 \%)$ & $443(14 \cdot 2 \%)$ & $2528(80.8 \%)$ & $3127(35 \cdot 1 \%)$ & 5783 & 8910 \\
\hline 6 - 10 years & $49(5 \cdot 6 \%)$ & $56(6 \cdot 4 \%)$ & $133(15 \cdot 2 \%)$ & $636(72 \cdot 8 \%)$ & $874(40 \%)$ & 1315 & 2189 \\
\hline 11 - 15 years & $52(7.9 \%)$ & $75(11.4 \%)$ & $112(17.1 \%)$ & $417(63 \cdot 6 \%)$ & $656(41 \cdot 4 \%)$ & 927 & 1583 \\
\hline Total & $166(3 \cdot 4 \%)$ & $23(4 \cdot 6 \%)$ & $717(14 \cdot 8 \%)$ & $3739(77 \cdot 2 \%)$ & $4845(36 \cdot 1 \%)$ & 8590 & 13435 \\
\hline
\end{tabular}

Key: 4+ - > 5000 parasites/ $\mu \mathrm{l}$ of blood; $3+-500-5000$ parasites $/ \mu \mathrm{l}$ of blood; $2+-50-500$ parasites/ $\mu \mathrm{l}$ of blood $1+-5-50$ parasites/ $\mu$ l of blood

FIGURE III: \% PARASITE DENSITY OF MALE CHILDREN

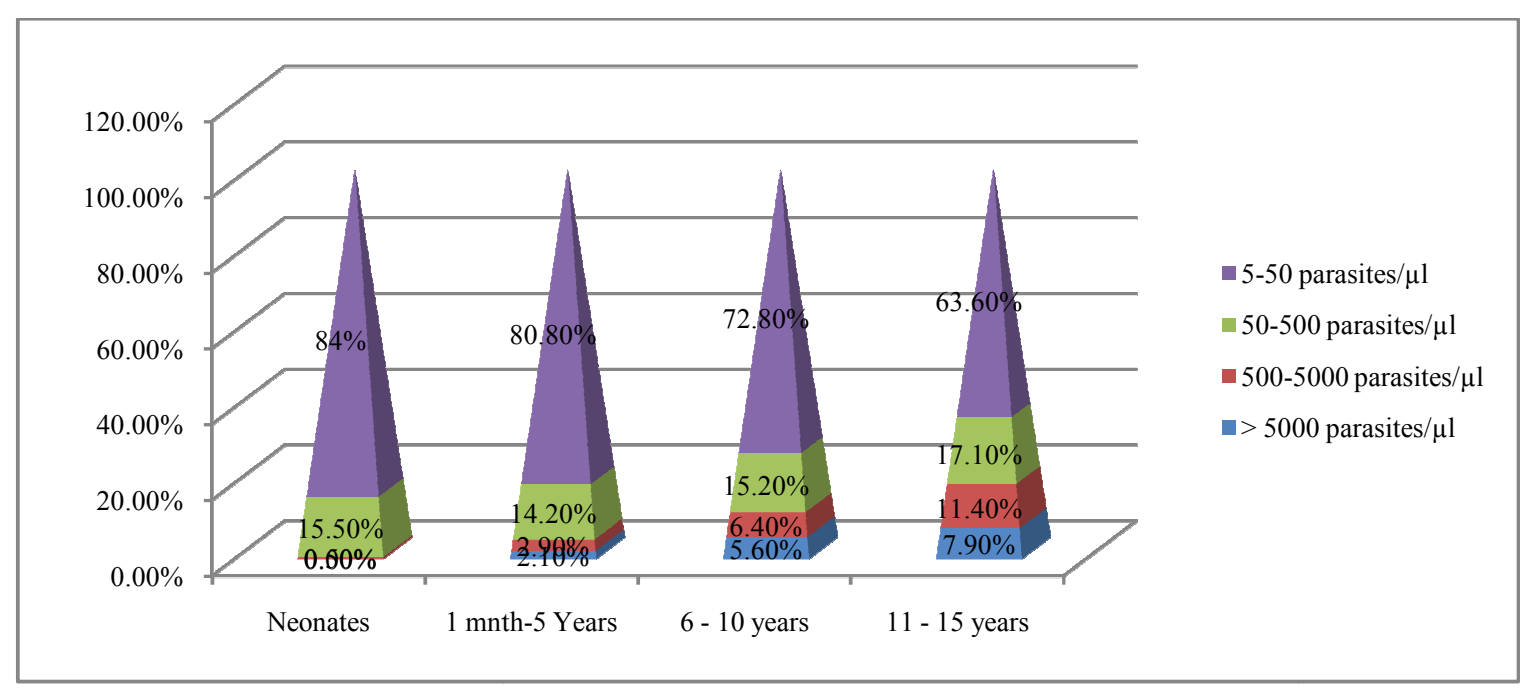

FIGURE IV: \% POSITIVITY OF AGE GROUPS AMONG MALE CHILDREN

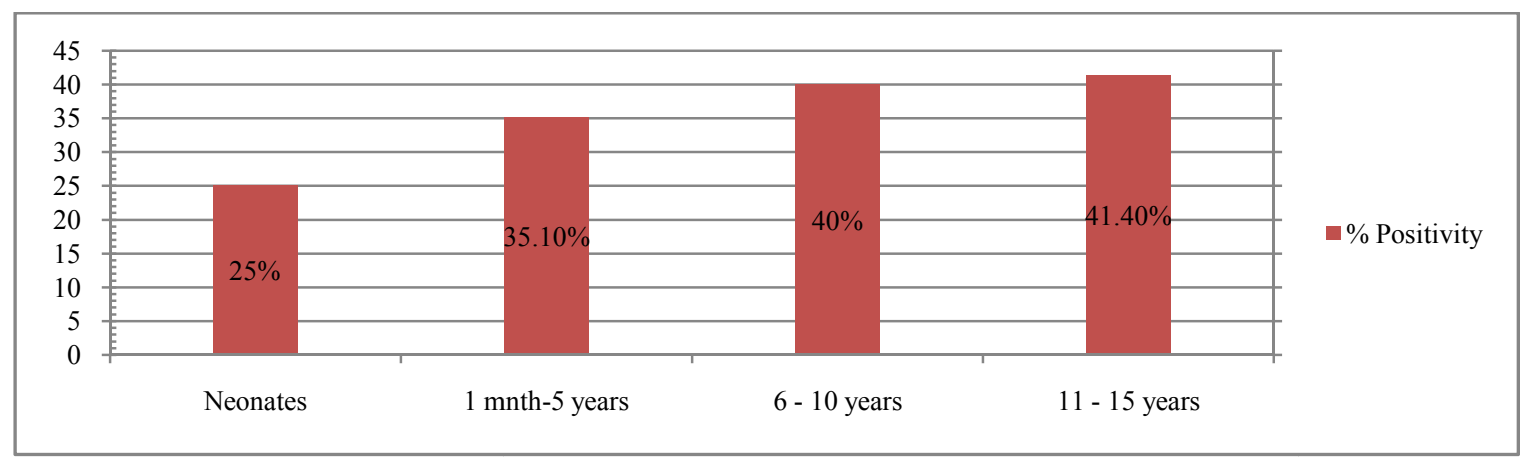


TABLE III: PREVALENCE AND PARASITE INTENSITY OF FEMALE CHILDREN

\begin{tabular}{|c|c|c|c|c|c|c|c|}
\hline Age Group & $4+$ & $3+$ & $2+$ & $1+$ & Total & Negatives & s Total No. \\
\hline & & & & & \multicolumn{2}{|c|}{ Positives } & Examined \\
\hline Neonates & $0(0 \%)$ & $1(0.9 \%)$ & $22(12 \cdot 9 \%)$ & $148(86.5 \%)$ & $171(27 \cdot 2 \%)$ & 457 & 628 \\
\hline 1mth - 5years & $43(1.8 \%)$ & $75(3 \cdot 1 \%)$ & $316(13.1 \%)$ & $1982(82 \%)$ & $2416(34.5 \%)$ & 4579 & 6995 \\
\hline $6-10$ years & $28(4 \cdot 2 \%)$ & $35(5 \cdot 2 \%)$ & $100(15 \%)$ & $508(75 \cdot 7 \%)$ & $671(36.5 \%)$ & 1169 & 1840 \\
\hline 11 - 15 years & $30(5 \cdot 3 \%)$ & $48(8.5 \%)$ & $107(19 \%)$ & $380(67.3 \%)$ & $565(40 \cdot 6 \%)$ & 826 & 1391 \\
\hline Total & $101(2 \cdot 6 \%)$ & $159(4 \cdot 2 \%)$ & $545(14 \cdot 3 \%)$ & $3018(78.9 \%)$ & $3823(35 \cdot 2 \%)$ & 7031 & 0854 \\
\hline
\end{tabular}

Key: $4+=>5000$ parasites $/ \mu \mathrm{l}$ of blood; $3+=500-5000$ parasites $/ \mu \mathrm{l}$ of blood; $2+=50-500$ parasites $/ \mu \mathrm{l}$ of blood; $1+=5-50$ parasites $/ \mu 1$ of blood

FIGURE V: \% PARASITE DENSITY OF FEMALE CHILDREN

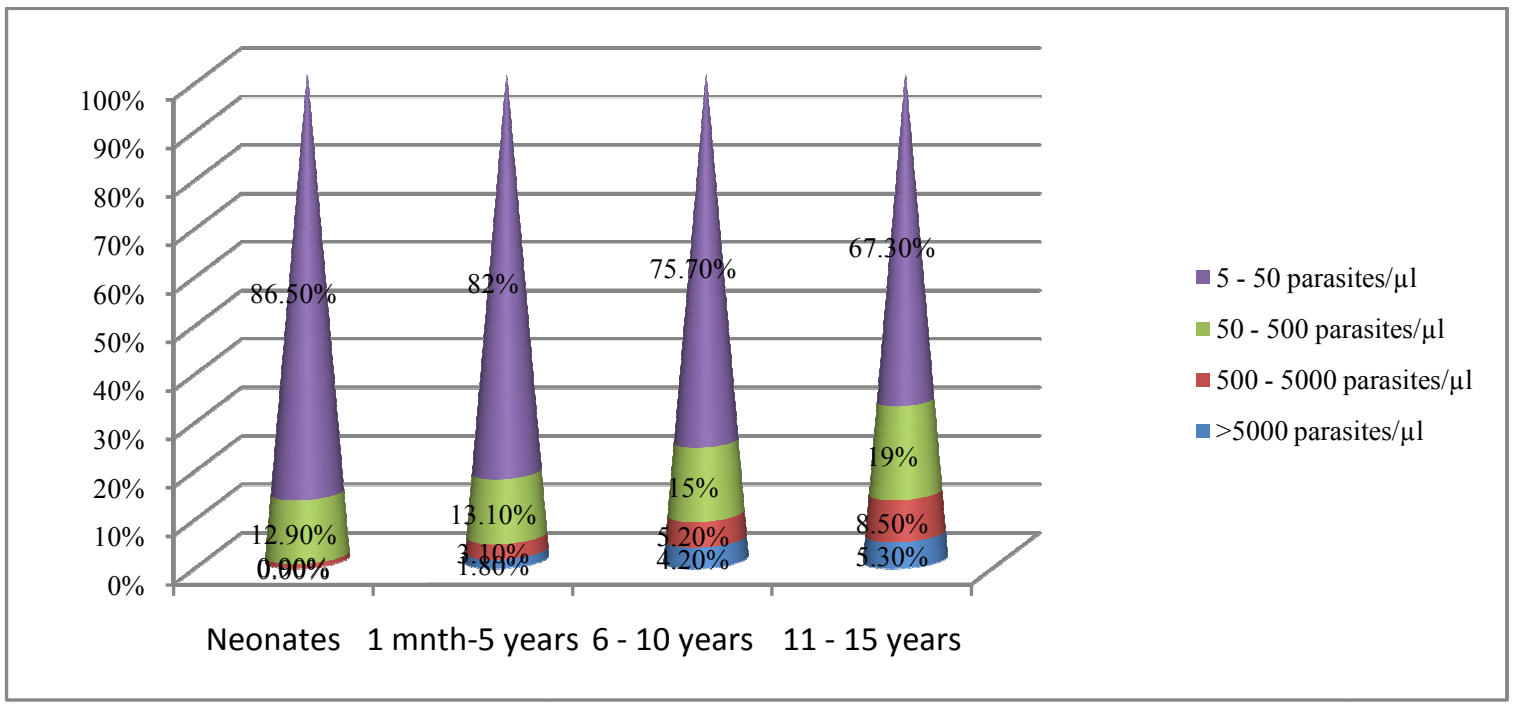

FIGURE VI: \% POSITIVITY OF AGE GROUPS AMONG FEMALE CHILDREN

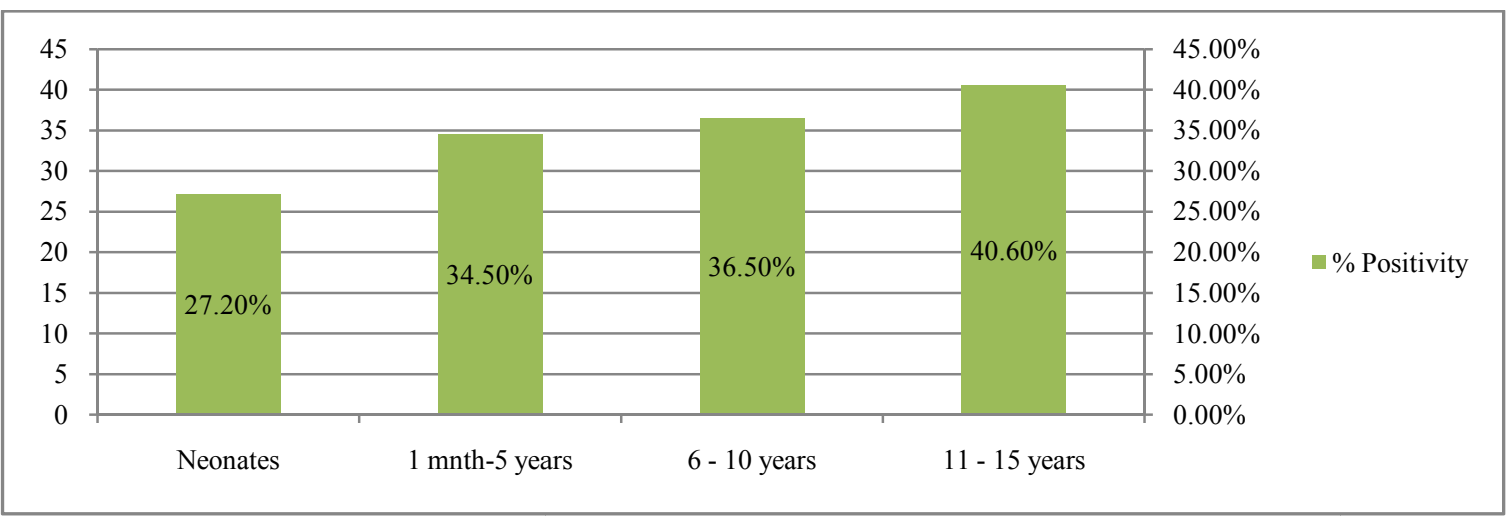




\section{DISCUSSION}

This study highlights the importance of prompt and accurate parasitological diagnosis of malaria amongst the paediatrics. Malaria parasites were found in 35.7\% of all age groups.

In 1971, Hendrickse et al (16) reported a 33.3\% prevalence rate in their study in Ibadan, Western Nigeria (now, South West Nigeria). In 1993, Pam et al, (17) reported a $41 \%$ prevalence rate for malaria among children that attended maternal and child welfare clinics in northern Nigeria. Ikeh et al, (2002) (15) had reported $29.3 \%$ positivity among paediatric patients in Jos. In 2006, Runsewe-Abiodun et al, (18) reported $24.8 \%$ malaria positivity among neonates and $17.4 \%$ for congenital malaria at Sagamu, Ogun State, South-west Nigeria. Oyedeji et al, (2010) (19) in their report stated that $20.3 \%$ of paediatrics had positive malaria test at Osogbo, South-West Nigeria. All these reports indicate that Nigeria is a mesoendemic country having a stable transmission being based on the WHO classification of endemicity revised by Metselaar and Van Thiel (1959) (20).

However, Okogun \& Amadi (2005) (21) reported that $95.2 \%$ of paediatric patients were confirmed positive for malaria parasites microscopically at a Nigerian tertiary health institution. We have not seen any other report that supports such very high percentage positivity among paediatrics in Nigeria.

In this study, although, the 1 month - 5 years age group (under fives) had most of the samples analyzed, $15,905(65.5 \%)$ of the 24,289; it had a \% positivity of $34.9 \%$. The $11-15$ years age group had the highest $\%$ positivity of $41.1 \%$, though with the second to last total number of samples examined, $2,974(12 \cdot 2 \%)$. From our data, it showed that a greater number of the blood samples analyzed (71.2\%) were those of the under fives including the neonates. This indicates that this group is more vulnerable or more hospital bound due to their low immune status than the older children between 6-15 years. $26 \%$ of neonates had malaria positivity rate while of the 6 10 years age group a $\%$ positivity of $38.3 \%$ was recorded.

The highest \% positivity of $41 \cdot 1 \%$ among the $11-15$ years age group may be attributed to the theory of innate immunity (9). In 2002, Ikeh et al, (15) reported $38.1 \%$ positivity amongst this age group.

The parasitaemia among neonates in this study $-26 \%$, most likely represents first infection and a good indication of recent transmission of malaria through transplacental infection or blood transfusion. We did not differentiate between congenital malaria from other neonatal malaria because we could not lay our hands on the folders of these patients as to identify those that had exchange blood transfusion.

In this study, no significant differences were found in prevalence and $\%$ positivity in relation to gender. While the male children had a \% positivity of $36.1 \%$, the female children had $35 \cdot 2 \%$.

Meanwhile, the continued use of malaria rapid diagnostic tests (M-RDTs) methodologies in Nigeria for individual diagnosis of malaria should be highly discouraged because of its negative implication. The implication of the continued use of these malaria rapid diagnostic tests (M-RDTs) methodologies includes underdiagnosis, misdiagnosis of malaria, mismanagement of non-malarial fever, which wastes limited resources, erodes confidence in the health care system, contributes to drug resistance, and eventual administration of unnecessary antimalarial drugs aimed at mopping up all negative test results where patients may still present with symptoms.

Several studies have shown that malaria rapid diagnostic tests (M-RDTs) methodologies have malaria parasites detection limit of 397 - 500 parasites $/ \mu$ l of blood and in some cases even more than 500 parasites/ $\mu 1$ of blood $(22,23,24,25,26,27$, 28) as against the 5 parasites/ $\mu$ l of blood detectable with the Giemsa stained slide microscopy examined by microscopists who are experienced and competent in the preparation and staining of blood films, as well as in the recognition and identification of the characteristic stages of malaria parasites usually found in human blood.

\section{Conclusion}

The missing component of the Roll Back Malaria (RBM) strategy - Laboratory Diagnosis should be incorporated. The vision of the current five-year strategic plan (2009 - 2013) is to ensure that Malaria no longer becomes a major public health problem in Nigeria as illness and death from malaria gets significantly reduced. This is to be achieved by ensuring that families will have universal access to malaria prevention and treatment. This latter aspect should rather read "access to malaria prevention, laboratory diagnosis and treatment.

There is need to enhance parasitological diagnosis by way of providing diagnostic tolls (both man-power and materials) at all levels of health care - primary (rural settings), secondary and tertiary. Above all, the turn-around time for malaria parasitological diagnosis should be drastically reduced so that such patients get their results same day and those with positive results see their doctors again for appropriate 
treatment before going back home. Appropriate antimalarial drugs for treatment should be given free to all malaria positive children.

\section{REFERENCES}

1. Patwari, A. (1985), Childhood Malaria. A Perspective. Post Graduate Doctor Africa, 7: 335 338.

2. Defo, B.K. (1995), Epidemiology and Control of Infant and Early Childhood Malaria: A competing risk analysis. Int J Epidemiology, 24: 204 $-17$.

3. Quinn, T.C., Jacobs, R.F., Mertz, G.J., Hook, I.I.I., Ocklsey, R.M. (1982), Congenital Malaria. A report of four cases and review. Journal of Paediatrics, 101: 229 - 252.

4. World Malaria Report 2012 (Report), World Health Organization.

5. Nadjm, B., Behrens, R.H. (2012) "Malaria: An update for physicians". Infectious Disease Clinics of North America, 26 (2): 243-59.

6. Oliver, C. (2012) "Global Malaria Mortality between 1980 and 2010: A Systematic Analysis", journalistsresource.org.

7. Murray, C.J., Rosenfeld, L.C., Lim, S.S., Andrews, K.G., Foreman, K.J., Haring,D., Fullman, N., Naghavi, M., Lozano, R., Lopez, A.D. (2012), "Global malaria mortality between 1980 and 2010: A systematic analysis". Lancet, 379 (9814): 413-31.

8. Hartman, T.K., Rogerson, S.J., Fischer, P.R. (2010), "The impact of maternal malaria on newborns". Annals of Tropical Paediatrics, 30 (4): 271- 82.

9. Federal Ministry of Health. National Antimalarial Treatment Policy 2008, Abuja. FMOH, National Malaria and Vector Control Division, 2008; Federal Republic of Nigeria.

10. Sodeinde, O., Dawodu, A.H. (1985), Neonatal Transfusional Malaria a Growing Clinical Problem. Nigeria J Paediatrics, 12: 57 - 60.

11. National Bureau of Statistics, Federal Republic of Nigeria, 2006 Population Census. Official Gazatte

(FGP 71/52007/2500(OL24): Legal Notice on Publication of the Details of the Breakdown of the National and State Provisional Totals 2006 Census. Available at: www.nigerianstat.gov.ng

12. World Weather Information Service, Abuja. (2004), Weather information for Abuja, Climatic Information 2004; Available at: http://www.worldweather.org.

13. Greenwood, B.M., Armstrong, J.R.M. (1991), Comparison of two simple methods for determining malaria parasite density.
Finally, if we must win this war against malaria, all unnecessary politicking associated with the prevention, accurate diagnosis at all levels of healthcare and effective treatment must be put aside.

Transactions of the Royal Society of Tropical Medicine and Hygiene, 85: 186-188.

14. Molineaux, L., Gramiccia, G. (1980), Research on the Epidemiology and Control of malaria in the Sudan Savanna of West Africa. The Gharki Project, WHO Geneva 1980. Available at: http://www.rbm.who.int.

15. Ikeh, E.I., Peletiri, I.C., Angyo, I.A. (2002), The prevalence and intensity of malaria parasite in children at Jos University Teaching Hospital, Nigeria. Highland Medical Research Journal, 1 (1): 9-10.

16. Hendrickse, R.G., Hassan, A.H., Olumide, L.O., Akinkumi, A. (1971), Malaria in early childhood. Ann Trop Med Parasitol. 65:1-20.

17. Pam, D.D., Imandeh, N.G., Ajayi, J.A. (1993), Malaria morbidity among children attending maternal and child welfare clinics in Northern Nigeria. Appl Parasitol. 34(3): 215-219.

18. Runsewe-Abiodun, I.T., Olusoga, B., Ogunfowora, O.B., Bolanle, M., Fetuga, B.M. (2006), Neonatal malaria in Nigeria -a 2 year review. BMC Paediatrics, 6: 19

19. Oyedeji, O.A., Oluwayemi, I.O., Afolabi, A.A., Bolaji, O., Fadero, F.F. (2010), Severe Malaria at a Tertiary Paediatric Emergency Unit in South West Nigeria. Research Journal of Medical Sciences, 4(6) 352 - 356.

20. Metselaar, D., Van Thiel, P.N. (1959), Classification of malaria. Trop Geogr Med. 11: 157 - 161.

21. Okogun, G.R., Amadi, A.N. (2005), Epidemiology, therapeutic agents and cost of management of paediatric malaria in a Nigerian tertiary hospital. Journal of Vector Borne Diseases, 42 (3): 87 - 94.

22. Mackey, L.J., McGregor, I.A., Paounova, N., Lambert, P.H. (1982) Diagnosis of Plasmodium falciparum infection in man: detection of parasite antigens by ELISA. Bull WHO, 60: 69 75.

23. Fortier, B., Delplace, P., Dubremetz, J.F., Ajana, F., Vernes, A. (1987), Enzyme immunoassay for detection of antigen in acute Plasmodium falciparum malaria. Eur J Clin Microbiol Infect Dis. 6: 596 - 8 .

24. Taylor, D.W., Voller, A. (1993), The development and validation of a simple antigen detection ELISA for Plasmodium falciparum malaria. Trans R Soc Trop Med Hyg. 87: 29-31. 
25. Piper, R.C., Vanderjagt, D.L., Holbrook, J.J., Makler, M. (1996), Malarial lactate dehydrogenase: target for diagnosis and drug development. Ann Trop Med Parasitol. 90: 433.

26. Tatfeng, Y.M., Bawo, D.D.S. (2008), Malaria Diagnosis in Nigeria: Of what relevance is Malaria Combo Rapid Diagnostic Kit? A paper presented at the $44^{\text {th }}$ Annual Scientific Conference of the Association of Medical
Laboratory Scientists of Nigeria at Bauchi 2008; paper 20, pp 48.

27. Adesanmi, T.A., Okafor, H.U., Okoro, A.B., Mafe, A.G. (2011), Diagnosis of malaria parasitemia in children using a rapid diagnostic test. Nigerian Journal of Clinical Practice, 14:195-200.

28. Peletiri, I.C., Ibecheozor, N.K.O. (2013), Malaria Status amongst some Patients at an Elite Hospital in Abuja, Nigeria. International Journal of Malaria Research E Reviews, 1:12-21. 